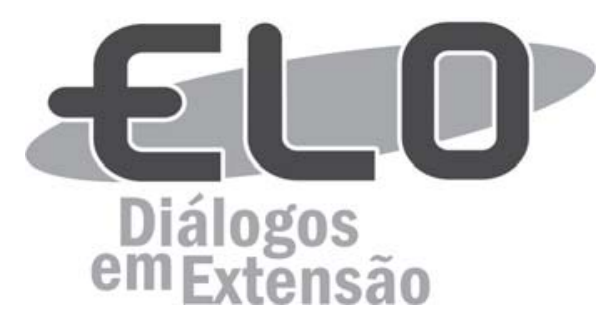

\title{
Intervenção musical no contexto hospitalar: a experiência do Guarda-Chuva Musical
}

\begin{abstract}
Giulianna Amador de Barros ${ }^{1}$, Luísa Volpato de Castilho ${ }^{1}$, Bianca Priuli Andrade ${ }^{2}$, Camilla Fernandes
\end{abstract} Passos Luquete ${ }^{3}$, Fernanda Melo de Oliveira ${ }^{4}$, Letícia Chiaramonte ${ }^{5}$, Rosana Ap. Salvador Rossit ${ }^{6}$

\begin{abstract}
Resumo: A equipe do Programa de Educação Tutorial - PET Saúde da Criança atua no contexto hospitalar com atividades lúdicas envolvendo a musicalização para tentar minimizar os efeitos causados pela hospitalização. Tem-se como objetivo, analisar a influência dessa intervenção para as crianças e seus acompanhantes na Pediatria/SUS da Santa Casa de Santos. A pesquisa qualitativa foi conduzida a partir de uma atividade tendo como recurso um guarda-chuva colorido, com palavras selecionadas previamente e penduradas, além de instrumentos sonoros. Cada participante escolhe uma palavra e lembra uma música para que todos cantem com o acompanhamento dos instrumentos. Ao fim da atividade, é aplicado um questionário aberto sobre percepções e sensações que emergiram a partir da atividade. Os resultados apontaram que a música interfere no espaço hospitalar proporcionando diferentes sensações. Destaca-se a importância dessa atividade, pois mobiliza o ambiente e as pessoas.
\end{abstract}

Palavras-chave: Pediatria. Hospital. Saúde da criança. Programa de Educação Tutorial. Pesquisa qualitativa. Área Temática: Saúde.

\section{Musical intervention in hospital context: the Experience Music Umbrella.}

Abstract: The Educational Tutorial Team (from Portuguese: Programa de Educação Tutorial) PET Child Health act in the hospital context with ludic activities involving music in order to reduce the effects caused by the hospitalization. The aim of the this study is to analyze and the influence of this musical intervation on the children and their attendant on the Santa Casa de Santos Pediatrics/SUS. The qualitative research was conducted from an activity containing a colorful umbrella, with pre-selected words hanged as rain water drops, as well as sonorous instruments. Each participant chooses one word and then remembers a song so everyone can sing together with the instruments. As the activity finishes, it is applied an open questionnaire about perceptions and sensations which emerged from the activity they performed. The results presented that the music interferes at the hospital environment providing different sensations, emotional expressions e Exchange of personal experiences. It is highlighted the importance of such activity by the fact it is an intervention, because it mobilizes the environment and the people, presenting itself as an action that allows expressions and feelings.

Keywords: Pediatrics. Hospital. Child Health. Programa de Educação Tutorial. Qualitative research.

\footnotetext{
${ }^{1}$ Discentes do curso de Psicologia da Universidade Federal de São Paulo

${ }^{2}$ Discente do curso de Serviço Social da Universidade Federal de São Paulo

${ }^{3}$ Graduada em Pedagogia pela Unimonte. Co-tutora do projeto.

${ }^{4}$ Discente do curso de Educação Física da Universidade Federal de São Paulo.

${ }^{5}$ Discente do curso de Terapia Ocupacional da Universidade Federal de São Paulo

${ }^{6}$ Professora Doutora do curso de Terapia Ocupacional na Universidade Federal de São Paulo. Tutora do projeto. Endereço: Rua Silva Jardim, 136, Vila Mathias,

Santos - SP. Telefone: (13) 981673980. Email: rorossit@hotmail.com
} 


\section{Intervención musical en el contexto hospitalario: la experiencia de paraguas musical}

Resumen: El equipo del Programa de Educación Tutorial - PET Salud Infantil (del portugués: Programa de Educação tutorial - PET Sáude da Criança), opera en hospitales con actividades recreativas vinculadas que utiliza la música para tratar de minimizar los efectos causados por la hospitalización. El objetivo es analizar la influencia de esta intervención para los niños y sus compañeros de Pediatría / SUS de Santa Casa de Santos. La investigación cualitativa se llevó a cabo de una actividad que tiene para ofrecer un paraguas de colores con palabras seleccionadas previamente, además de utilizar algunos instrumentos. Cada participante elige una palabra y tiene que recordar una canción para que todos canten con el acompañamiento de instrumentos. Al final de la actividad, se aplica un cuestionario abierto sobre las percepciones y sentimientos que surgieron de la actividad. Los resultados mostraron que la música interfiere en los hospitales que proporcionan diferentes sensaciones. Es importante resaltar la importancia de esta actividad, porque moviliza el medio ambiente y las personas.

Palabras clave: Pediatría. Hospital. Salud infantil. Programa de Educación Tutorial. Investigación cualitativa.

\section{Introdução}

O Programa de Educação Tutorial (PET) é um programa acadêmico destinado a estudantes de cursos superiores públicos e privados, tendo como requisito a indissociabilidade entre ensino, pesquisa e extensão com atividades articuladas e orientadas por um professor-tutor (MARTINS e KETZER, 2008). O PET articula os princípios da indissociabilidade na perspectiva de integrar ações desenvolvidas para a formação profissional do estudante e pela produção e difusão de conhecimentos provenientes da experiência vivenciada, de modo a possibilitar espaços e oportunidades de conhecimento e aprendizagens que ultrapassam os limites físicos da estrutura acadêmica universitária.

O Projeto Pedagógico do campus Baixada Santista da Universidade Federal de São Paulo (UNIFESP) está voltado à formação de um profissional da área da saúde apto para o trabalho em equipe interprofissional, com ênfase na integralidade do cuidado, entendendo a relação com a comunidade como propulsora do ensino e da aprendizagem. O PET Saúde da Criança da UNIFESP baseia suas ações nos princípios da educação interprofissional valorizando o trabalho em equipe e a integração no processo de ensino e nas atividades de pesquisa e extensão, respeitando a especificidade da formação de cada profissão, onde profissionais aprendem juntos sobre o trabalho conjunto e sobre as especificidades de cada um, na melhoria da qualidade do cuidado ao paciente (UNIFESP, 2006; BARR, 1998).

A aproximação do aluno a ambientes que demandam a atuação de equipes interprofissionais, potencializa a aprendizagem e contribui para a melhoria da qualidade e prestação dos serviços à comunidade, valorizando as relações interpessoais e desenvolvendo habilidades para a escuta, o diálogo e o acolhimento. A percepção e a análise da multicausalidade dos processos de adoecimento e dos fatores que influenciam o desenvolvimento infantil tornam-se alvo de ensino, pesquisa e extensão do PET - Saúde da Criança. Visto que o adoecer e a hospitalização são fatores que alteram os sentimentos e os comportamentos dos indivíduos, pois muitas vezes a criança fica restrita ao leito, submetida à passividade, cercada de fatores que lhe causam dor e sofrimento, como imagens, cheiros e sons estranhos no hospital, que podem ser ameaçadores e confusos para essas crianças (OLIVEIRA; DANTAS; FONSÊCA, 2004; GORAYEB, 2012). Nesse sentido, verifica-se a necessidade de entender o hospital com o mesmo olhar da criança, para se criar estratégias que possam minimizar o sofrimento causado pelo ambiente hospitalar.

$\mathrm{Na}$ tentativa de desviar a atenção dos aspectos relacionados à doença e ao sofrimento físico e emocional, provocados pela condição de hospitalização para uma situação mais agradável e interessante, o PET Saúde da Criança oferece a oportunidade às crianças e seus acompanhantes de se envolverem em atividades lúdicas durante o período de internação. A atuação no espaço hospitalar auxilia na mudança de comportamentos dessa população e proporciona benefícios para além da atenção à doença. Atualmente, evidencia-se a tendência crescente, onde o espaço hospitalar busca incluir a música como valor social e terapêutico, na tentativa de minimizar o afastamento do cotidiano, medo, apatia ou ainda sentimentos de fuga, culpa e tristeza (FERREIRA; REMEDI; LIMA, 2006). 
[...] a internação hospitalar na fase infantil pode desencadear sérios problemas, seja de conduta ou até mesmo psicológico. Nesse sentido, essas dificuldades só serão amenizadas com o processo de socialização do paciente, no qual este possa estar em contato com outras crianças e em um ambiente agradável. Percebe-se ainda a necessidade de atividades lúdico-pedagógicas favorecendo com o processo de desenvolvimento infantil e amenizando o desconforto, que muitas vezes é acometido no hospital. A música auxilia na redução da tensão e da ansiedade, além de contribuir para a diminuição da dor e melhorar a qualidade do sono. (PIOVESAN, SILVA, 2014, p. 5)

A intervenção musical tem como objetivo a promoção de um sentimento de bem-estar, melhorar o humor, alcançar o relaxamento e não necessita de um profissional musicoterapeuta (PETROVSKY; CACCHIONE; GEORGE, 2015). A música pode ser utilizada como um recurso adicional em um processo terapêutico, pois contribui para a humanização destes espaços podendo criar momentos de prazer e bem-estar, sensibilizando os pacientes para novas experiências artísticas e culturais (CUNHA e VOLPI, 2008). Como um recurso de intervenção no ambiente hospitalar, a música poderá proporcionar um ambiente mais descontraído e agradável, trazendo um relaxamento físico e mental, já que pode reduzir o estresse, a tensão e a ansiedade (BERGOLD e ALVIM, 2004).

De acordo com o Instituto Nacional de Câncer (2009), quando se unem as canções às crianças, o objetivo é proporcionar um retorno ao ambiente aconchegante de casa, além de promover o desenvolvimento psicomotor, a expressão de sentimentos, de voltar a ser criança, de brincar e gastar energia.

A Santa Casa de Misericórdia de Almada, desde 2005 possui o projeto "Música nos Hospitais", no qual a Associação Portuguesa de Música nos Hospitais e Instituições de Solidariedade realiza semanalmente as intervenções utilizando a música como forma de criar momentos prazerosos, de cuidado e de bem-estar para funcionários e pacientes. Estas intervenções musicais ocorrem de forma regular, uma vez por semana, e implicam no trabalho de uma dupla de músicos com formação específica para tal. Os músicos circulam pelos espaços da instituição, interpelando pacientes, familiares, visitantes e profissionais, despertando ou recorrendo para a parte saudável das pessoas, através da música. Introduzem-se momentos de ruptura na rotina da instituição, proporcionando um espaço sensível, facilitador da expressão das emoções e do diálogo, tornando os espaços e ambientes mais humanizados (Santa Casa da Misericórdia de Almada, 2014).

\section{Objetivos}

Analisar a influência da intervenção musical na Pediatria/SUS da Santa Casa de Santos na percepção das crianças e seus acompanhantes. Verificar se há relação entre a intervenção musical e as sensações e sentimentos provocados nas crianças hospitalizadas, bem como as percepções dos acompanhantes acerca dos seus sentimentos, lembranças e emoções.

\section{Percurso metodológico}

O PET Saúde da Criança da UNIFESP campus Baixada Santista conta com a participação de 15 estudantes dos cursos de graduação em educação física, fisioterapia, nutrição, psicologia, serviço social e terapia ocupacional, um co-tutor e um tutor. A educação interprofissional dos estudantes é um diferencial na formação e um dos aspectos fundamentais para que possam aprender juntos para no futuro poderem trabalhar em equipe nos diferentes cenários de prática profissional. Pensar em novas interações no trabalho em equipe configura-se como ricas oportunidades de trocas de experiências e saberes numa postura de respeito à diversidade e cooperação para efetivar práticas transformadoras. (UNIFESP, 2006).

Trata-se de uma pesquisa qualitativa descritiva, que tem como objeto de análise a atividade realizada com o w Musical com crianças e acompanhantes internados na Pediatria/SUS da Santa Casa da Misericórdia de Santos-SP, como uma das ações desenvolvidas pelo PET Saúde da Criança, que visa a 
promoção e prevenção da saúde da criança hospitalizada. O projeto teve aprovação do CEP UNIFESP $\mathrm{n}^{\mathrm{o}}$ 0720/11. Foram realizadas duas intervenções musicais entre o período do segundo semestre de 2015 e o primeiro semestre de 2016. Os relatos coletados foram de 19 acompanhantes e 12 crianças, selecionados de acordo com a sua disponibilidade, visto que a rotina hospitalar não permitia que alguns ficassem até o término da atividade.

Um guarda-chuva colorido com as cores do arco-íris e alguns instrumentos musicais de uma bandinha infantil, como triângulo, tambor, chocalho, guizos, entre outros, são utilizados como recursos visual e auditivo. Os estudantes prepararam os recursos, confeccionando palavras e figuras que são penduradas no guarda-chuva e aleatoriamente escolhidas pelos participantes, e selecionando os instrumentos apropriados.

Esta atividade musical é realizada no espaço externo da ala pediátrica, onde crianças e acompanhantes se reúnem para participar, cantando músicas a partir de palavras-chave que desencadeiam a lembrança de diferentes canções e tocando instrumentos sonoros simples que são distribuídos e utilizados como acompanhamento às canções.

Como procedimento, solicita-se que um participante (criança ou acompanhante) escolha uma palavra ou figura, e em seguida, cante uma música que contenha a respectiva palavra. Caso o participante não recorde uma música, solicita-se a colaboração das demais pessoas presentes. As músicas são acompanhadas pela "bandinha". Ao final da atividade, para a coleta de dados, os participantes são convidados (individualmente) a expressar a sua opinião em relação ao momento vivenciado, relatando percepções e sensações que emergiram a partir da atividade de cantar, tocar ou apenas ouvir as músicas. Os estudantes explicam que a participação é voluntária e que eles têm total liberdade de aceitar ou não, sem que isso acarrete qualquer prejuízo. Esclarece-se que as informações são confidenciais e que seu nome não será divulgado em hipótese alguma. Os acompanhantes serão denominados pelo grau de parentesco seguido do número sequencial do relato e as crianças pela inicial do nome e a idade. Nas fotos a seguir, observa-se o manuseio do Guarda-Chuva pelo petiano e a formação da bandinha pelas crianças.

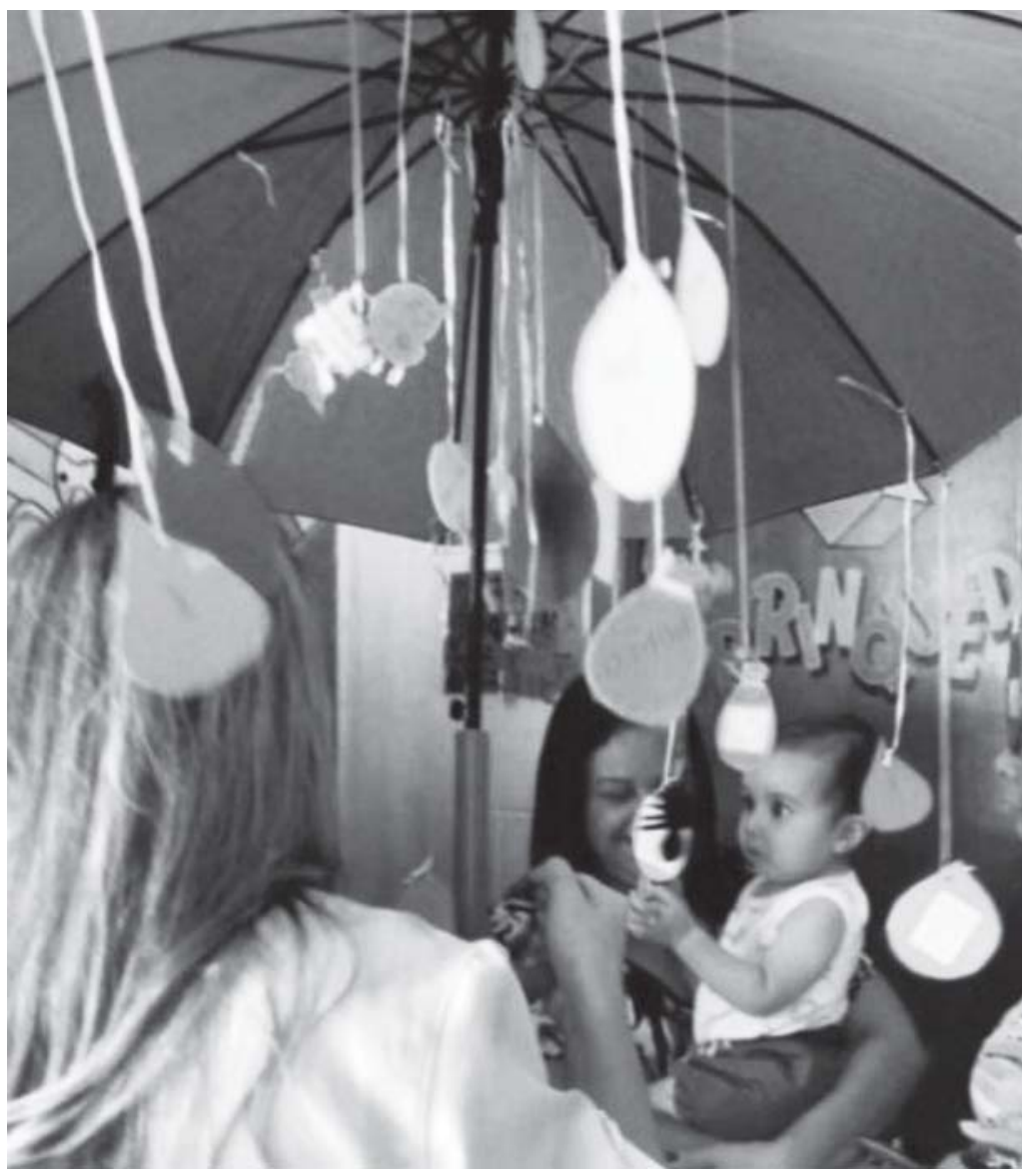

Figura 1 - Guarda-chuva musical.

Fonte: O autor (2015). 


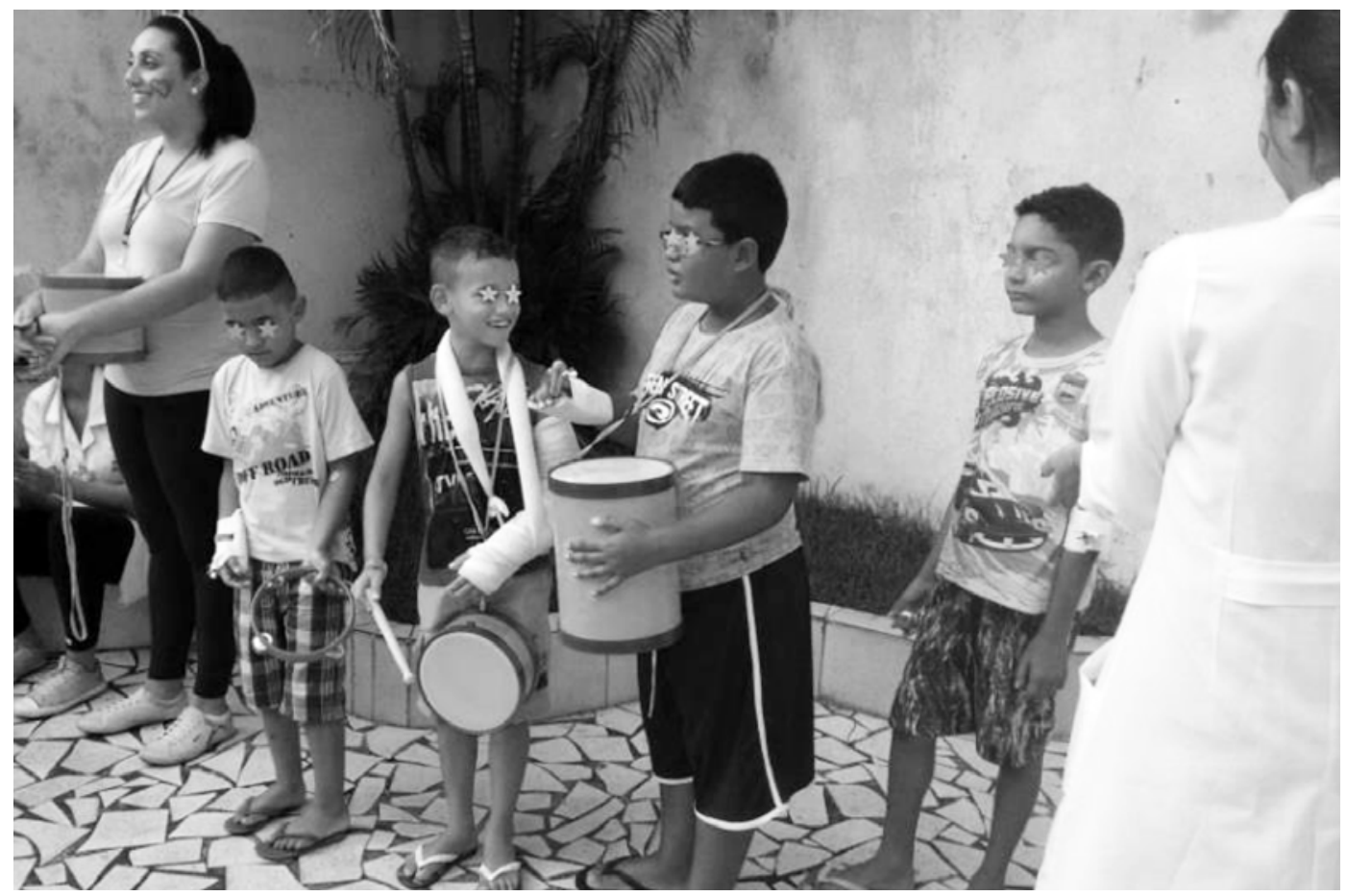

Figura 2 - Bandinha das crianças.

Fonte: O autor (2015).

Os relatos foram registrados no formato de texto para possibilitar a análise qualitativa descritiva. Os dados foram coletados no segundo semestre de 2015 e primeiro semestre de 2016, analisados e categorizados.

Minayo (2010) afirma que a pesquisa qualitativa responde a questões muito particulares, ela se ocupa, nas Ciências Sociais, com um nível de realidade que não pode ou não deveria ser quantificado uma vez que trabalha com o universo dos significados, dos motivos, das aspirações, das crenças, dos valores e das atitudes. Esse conjunto de fenômenos humanos é entendido como parte da realidade social, pois o ser humano se distingue não só por agir, mas por pensar sobre o que faz e por interpretar suas ações dentro e a partir da realidade vivida e por partilha com seus semelhantes.

Segundo Gil (1991), a pesquisa descritiva visa descrever as características de determinada população ou fenômeno ou o estabelecimento de relações entre variáveis. Envolve o uso de técnicas padronizadas de coleta de dados, além de prever um complemento analítico que merece atenção, uma vez que contém uma análise crítica do pesquisador em relação às ideias expressas.

\section{Resultados e Discussão}

A intervenção musical realizada na Santa Casa de Santos-SP visou propiciar um espaço dinâmico e acolhedor em busca da expressão e da qualificação do cuidado às crianças hospitalizadas e seus acompanhantes, sendo uma intervenção de baixo custo, não-farmacológica e não-invasiva. Buscou-se por meio do recurso musical proporcionar momentos de descontração e alegria para as crianças e seus acompanhantes com o intuito de amenizar a angústia e a dor no caso de internação hospitalar. Podese perceber isto quando o Pai 15 relata que "é um momento de descontração tanto para as mães, como para as crianças. É uma felicidade para ele (seu filho), porque o hospital é um sofrimento". Alguns revelam também, que a musicalização auxilia para a redução do tempo ocioso presente no hospital e que ajuda na melhora de seus filhos e na mudança de comportamento. Isto pode ser observado nas falas da Mãe 11, que diz que sua filha "voltou toda animada, voltou de outro jeito", e do Pai 03 que afirma que "lá a gente até esquece que está doente".

Observa-se que para as crianças, a alegria e descontração também se evidenciam no momento da intervenção, para uma criança de 7 anos, ela refere que auxilia na melhora do ambiente hospitalar. Outra criança de 8 anos diz que a participação na atividade proporcionou uma percepção que "nem parecia que estava no hospital". 
Destaca-se também que a interdisciplinaridade, caracterizada pelas ações interprofissionais e interinstitucionais, com consistência teórica e operacional configura-se como um diferencial na formação técnico-científica, pessoal e social do estudante, em consonância com os pressupostos do Projeto Pedagógico do campus Baixada Santista: integralidade no cuidado, formação interprofissional, metodologias ativas de ensino, aprendizagem colaborativa e significativa, trabalho em equipe. As experiências vivenciadas pelos estudantes em formação possibilitam aprendizagens para além do espaço físico da estrutura universitária, gera produtos e/ou processos de publicação e apresentação pública dos resultados. (UNIFESP, 2006).

Os dados possibilitaram a organização dos relatos em núcleos temáticos, categorias e subcategorias emergentes, conforme é listado a seguir.

\section{1 - Ambiente de descontração}

\section{1 - Momentos de Alegria e Diversão}

\subsection{1 - Percepção dos acompanhantes}

Adorei essa equipe da alegria. Todos deveriam dispor do seu tempo como essas meninas lindas, exemplo para muitos. Obrigada. (Mãe 8).

Alegria, felicidade, descontração. Deus abençoe vocês por tudo. (Mãe 10).

Bom... é muito legal porque as crianças em tratamento se divertem um pouco. Obrigada (Mãe 12).

Atividade divertida e trabalha a memória (Mãe 13)

Brincadeira muito criativa e gostosa, anima pais e crianças! Parabéns! (Pai 14).

\subsection{2 - Percepção das crianças}

Gostei tia! Gostei da dança! (Cr 1, 3 anos).

Gostei! Foi animado! (Cr 2, x anos).

Eu gostei de cantar as músicas! (Cr 3, 4 anos).

Achei legal. Eu nunca tinha brincado com essa brincadeira. ( $\mathrm{Cr}$ 6, 7 anos).

\subsection{3 - Memórias de ambientes agradáveis}

Eu gostei, elas se sentem em casa. Vocês estão de parabéns! (Mãe 1).

Eu gostei, senti alegria, nem parecia que estava no hospital. (Cr 8, 8 anos).

Eu gostei muito, parecia que era na escola, no primeiro ano. Valeu a pena! Fiquei com saudades dos meus irmãos e melhorei um pouco. ( $\mathrm{Cr} 9,8$ anos).

A música possui grande subjetividade, pois emerge como um testemunho histórico. Expressa uma cultura e é, simultaneamente, expressão cultural. Contextualizada numa dimensão espaçotemporal, a canção emerge como um campo de forças. Isto possibilita lê-la, não a partir do que poderia existir intrinsecamente nela, mas procurando perceber as formas diversas de apropriação a qual ela está submetida. Em outras palavras, uma forma cultural que promove sociabilidades, visões de mundo, representações sociais compostas no tempo e no espaço (FILHO, 2001). No entanto, a área hospitalar tende a considerar científico somente o que pode ser mensurável, relegando a subjetividade. Apesar deste fato, o grupo PET presencia de perto a tendência crescente que o espaço hospitalar possa incluir a música, como valor social, terapêutico e inclusive, na tentativa de minimizar a ruptura e o afastamento 
do cotidiano, medo, culpa e tristeza. Porém, ainda hoje, existem poucas referências bibliográficas que comprovem os benefícios que a intervenção musical proporciona, assim surge a necessidade de se elaborar pesquisas, na qual se somem a outros atributos técnicos que valorizem a subjetividade (FERREIRA; REMEDI; LIMA, 2006).

\section{2 - Hospital}

\section{1 - Processo de hospitalização}

\subsection{1 - Dificuldades enfrentadas}

Momento de descontração tanto para as mães, como para as crianças. É uma felicidade para ele, porque o hospital é um sofrimento. (Mãe 7).

Um trabalho excepcional de todo o grupo, animando as crianças em um momento tão difícil de recuperação, seria muito bom ter a visita mais vezes. (Pai 5).

\subsection{2 - Tempo ocioso}

Bem legal, porque aqui não tem nada para se fazer!. (Mãe 4).

Eu gostei, porque faz a gente ficar feliz, não temos nada para fazer. (Cr 10, 11 anos).

\section{3 - Benefícios}

\section{1 - Fator de bem-estar}

Ajuda na melhora da criança. (Mãe 4).

Ótimo, maravilhoso, ajuda muito na recuperação das crianças. (Avó 9).

Bom... é muito legal porque as crianças em tratamento se divertem um pouco. Obrigada! (Pai 15).

Achei legal, gostei, fiquei alegre. Melhora estar no hospital. (Cr 11, 7 anos).

\section{2 - Fator de mudança}

\subsection{1 - Comportamento/Emoção}

$\mathrm{Eu}$ acho muito bom o trabalho de vocês. Ele estava meio tristinho, pra baixo, e lá serviu como descontração. Continuem com o projeto. (Mãe 2).

Legal o projeto, continuem fazendo. Ela voltou toda animada, voltou de outro jeito. (Mãe 3).

Gostei. Estava triste, voltei alegre. (Cr 12, 4 anos).

\subsection{2. - Esquecimento das dores}

Muita criança doente, e lá a gente até esquece que está doente. Você viu que só dava eu cantando, ne? E com vocês cantando as crianças animam, cantaram a galinha pintadinha e o P. animou muito. (Mãe 4). 
Muito boa! Assim as crianças esquecem um pouco das dores. Parabéns pela iniciativa! (Pai 11).

As interações musicais em ambiente hospitalar, tem contribuído para a humanização destes espaços, podendo criar momentos de prazer e bem-estar, sensibilizando os pacientes para novas experiências artísticas e culturais (CUNHA, 2008).

Brincar é a função básica da criança. Através da brincadeira, ela pode explorar, aprender e fazer descobertas sobre o mundo que habita. O processo de internação altera a rotina da criança, incluindo o seu brincar e sua motivação (ANAIS DO VII ENCONTRO DE EXTENSÃO DA UNIVERSIDADE FEDERAL DE MINAS GERAIS, 2004). A brincadeira é essencial para o desenvolvimento infantil, por promove processos de socialização e descoberta do mundo, como mostram as fotos abaixo.

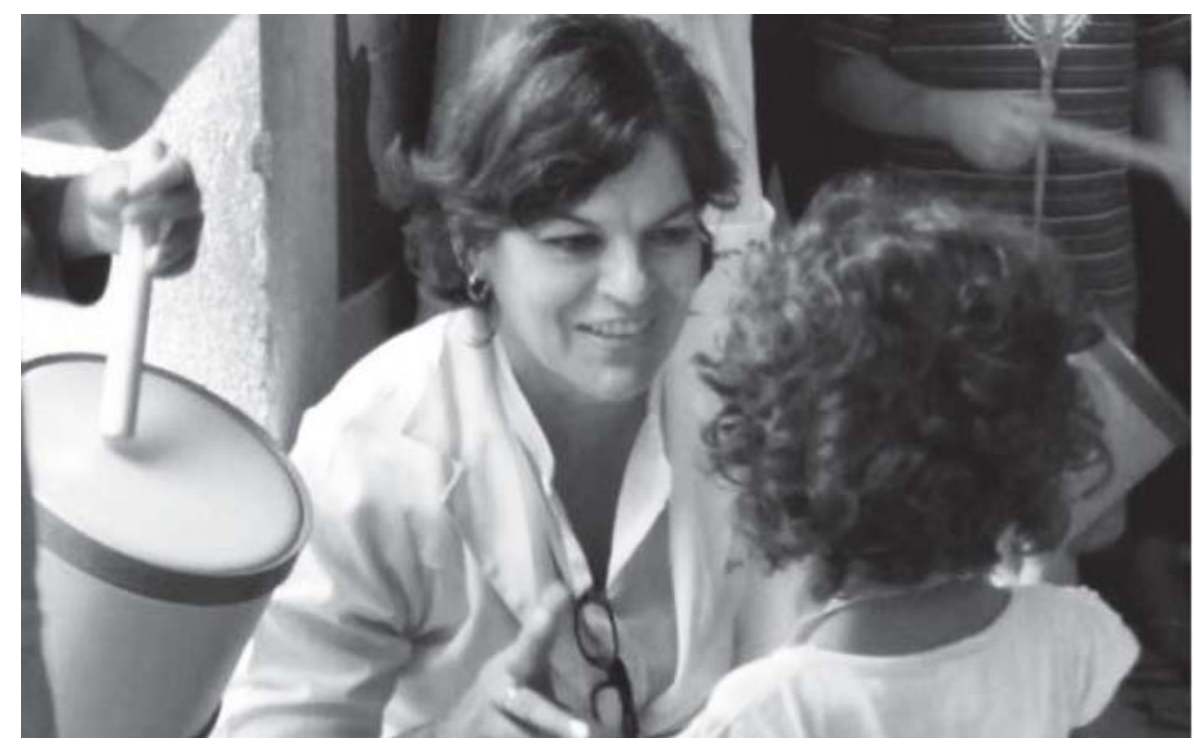

Figura 3 - Participação do tutor.

Fonte: O autor (2015).

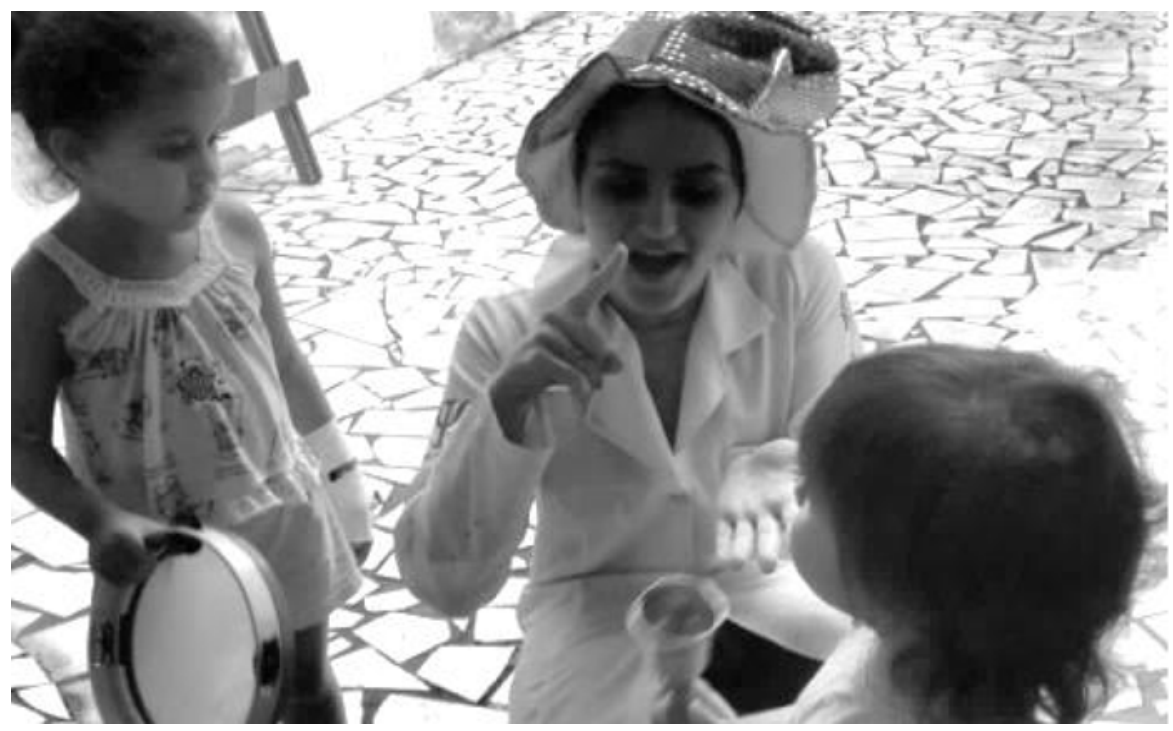

Figura 4 - Participação do discente.

Fonte: O autor (2015).

De acordo com Silva e Piovesan (2014), desde os tempos antigos até os dias atuais, o lúdico está presente na vida das crianças, os jogos, brincadeiras e brinquedos desempenham um papel essencial na construção do ser. Desse modo, pode-se afirmar que o brincar é mais um meio de contribuição para o processo de reabilitação e cura da criança e-a música, a qual também é um desses recursos, possibilita o equilíbrio de tensões, trabalha as necessidades cognitivas, psicológicas e propicia a constituição de conhecimentos e desenvolvimento das estruturas mentais, uma vez que cria uma relação com o 
brinquedo e a atividade lúdica.

As reações da criança no período de internação propiciam o desenvolvimento de quadros ansiosos e alterações emocionais, sendo necessário refletir sobre essas mudanças e propor estratégias para minimizar o impacto da internação (AZEVEDO, 2011).

Assim, é necessário oferecer condições de desenvolvimento para as crianças, ampliando e valorizando as oportunidades de brincar. O guarda-chuva musical, bem como as atividades lúdicas oferecidas pelo PET Saúde da Criança, contribui para o processo de desenvolvimento da criança, que pode ser prejudicado durante uma internação hospitalar, onde o sofrimento e a angústia podem ser facilmente presentes no cotidiano das crianças e acompanhantes. Tornando-se uma responsabilidade e, ao mesmo tempo, um desafio, a intervenção musical se mostra como um recurso que permite expressões afetivas significativas para um melhor bem-estar na internação, pois é um instrumento de cuidado tanto à criança, como para os acompanhantes que potencializa as emoções e a troca de vivências, através de uma maior sensibilização (MARCOLINO et. al, 2011).

\section{Conclusão}

O presente estudo teve como objetivo analisar a influência da intervenção musical na Pediatria/ SUS da Santa Casa de Santos na percepção das crianças e seus acompanhantes. Observou-se que a música tem a capacidade de aliviar o sofrimento e a dor tanto para as crianças como para os acompanhantes, assumindo um efeito terapêutico e remediativo da condição de hospitalização.

É importante ressaltar que a interdisciplinaridade deve estar inerente às práticas de assistência à saúde infantil, pois os primeiros anos de vida são imprescindíveis para o cuidado à saúde integral no decorrer dos anos do indivíduo.

Os resultados revelaram que a intervenção musical na Pediatria/SUS trouxe benefícios tanto físicos quanto emocionais para crianças e acompanhantes, promovendo um ambiente descontraído e agradável. Este resultado foi alcançado a partir das ações interprofissionais com os estudantes de seis diferentes profissões da área da saúde e interinstitucionais por meio da parceria da Universidade Federal de São Paulo com a Santa Casa da Misericórdia de Santos, possibilitando as aprendizagens para além dos muros da universidade e buscando uma atenção centrada nas necessidades da clientela e na promoção da saúde física e mental de todos os envolvidos.

\section{Fontes de financiamento}

Agradecemos ao MEC/SESu/PET pelo financiamento das atividades realizadas, por meio de bolsas aos petianos e tutor.

\section{Agradecimentos}

Agradecemos a todos os outros petianos que colaboraram com a realização da atividade para que ela pudesse ser analisada pelas crianças e seus acompanhantes. Agradecemos também à Santa Casa de Misericórdia de Santos, por nos ceder o espaço da pediatria para realizarmos todas as nossas atividades.

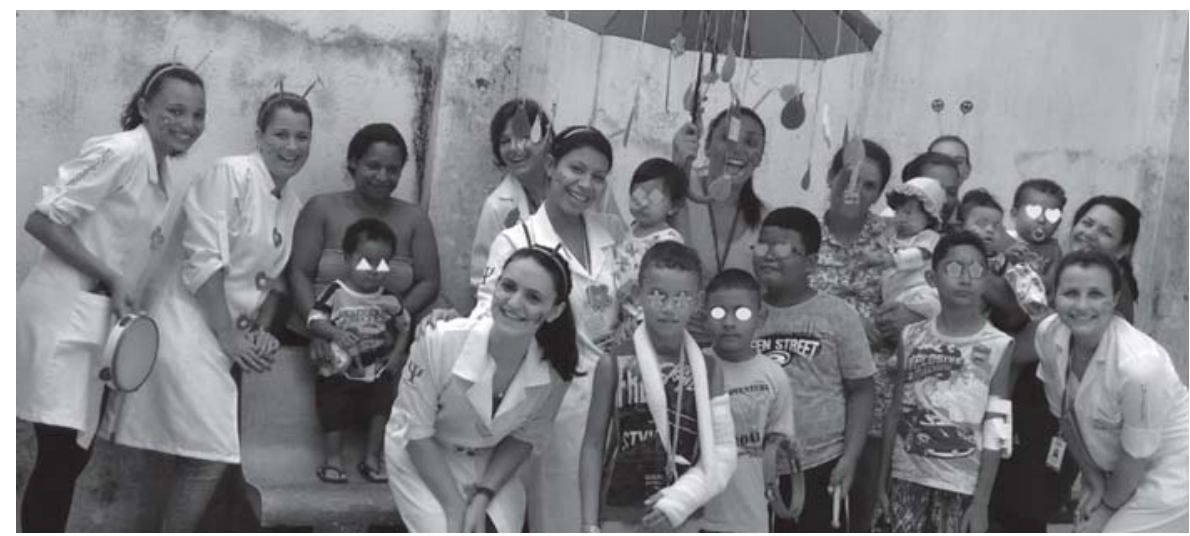

Figura 5 - Realização da atividade Guarda-Chuva Musical.

Fonte: O autor (2015). 


\section{Referências Bibliográficas}

AZEVEDO, Adriano Valério dos Santos. O brincar da criança com câncer no hospital: análise da produção científica. Estud. psicol. (Campinas), Campinas, v. 28, n. 4, p. 565-572, Dec. 2011.

BARR, H. Competent to collaborate: Towards a competency-based model for interprofessional education. Journal of Interprofessional Care, v. 12, n. 2, p. 181-188, 1998.

BERGOLD, L. B.; ALVIM, N. A. T. Música e enfermagem: uma integração possível no cuidado hospitalar. Rio de Janeiro, 2004.

BRASIL. Instituto Nacional de Câncer. A terapia da música, 2009. Disponível em: <http:// www2.inca.gov.br/wps/wcm/connect/631565004eb6925285e097f11fae00ee/13_social.pdf? MOD=AJPERES>. Acesso em: 19 jul. 2016.

CUNHA, R.; VOLPI, S. A prática da musicoterapia em diferentes áreas de atuação. Revista científica/ FAP, Curitiba, v. 3, p. 85-97, jan./dez. 2008.

FERREIRA, C. C. M.; REMEDI, P. P.; LIMA, R. A. G. A música como recurso no cuidado à criança hospitalizada: uma intervenção possível?. Revista Brasileira de Enfermagem, v. 59, n. 5, p.689-693, set./out., 2006.

FILHO, W. H. Educação dos sentidos: música e subjetividade. OPSIS - Revista do Niesc, v. 1, p. 917, 2001.

GIL, Antonio Carlos. Como elaborar projetos de pesquisa. São Paulo: Atlas, 1991.

GORAYEB, R et al. Ansiedade e Depressão Pré-Cirúrgica numa Enfermaria de Ginecologia Oncológica e Mastologia. Psicologia, Saúde E Doenças, Lisboa, v. 13, n. 2, p. 145-156, 2012.

MARCOLINO, E. C. et. al. A interdisciplinaridade como ferramenta na promoção à saúde da criança. In: XV ENCONTRO LATINO AMERICANO DE INICIAÇÃO CIENTÍFICA E XI ENCONTRO LATINO AMERICANO DE PÓS-GRADUAÇÃO, 2011, São José dos Campos. Anais. São José dos Campos: Universidade do Vale do Paraíba, 2011.

MARTINS, I. M. L. (Org.); KETZER, S. M. (Org.). Programa de Educação Tutorial: estratégia para o desenvolvimento da graduação. 1. ed. Brasília, DF: Brasil Tropical, 2008.

MINAYO, Cecília de Souza (Org). Pesquisa social: teoria método e criatividade. Petrópolis: Vozes, 2010.

OLIVEIRA, G. F.; DANTAS, F. D. C.; FONSECA, P. N. O impacto da hospitalização em crianças de 1 a 5 anos de idade. Rev. SBPH. vol.7, n.2, pp. 37-54, 2004

PETROVSKY, D.; CACCHIONE, P.Z.; GEORGE, M. Review of the effect of music interventions on symptoms of anxiety and depression in older adults with mild dementia. Pennsylvania, p 1-10, 2015.

SANTA CASA DA MISERICÓRDIA ALMADA, 2014. Música nos hospitais. Disponível em: < http:// www.scma.pt/musica-nos-hospitais>. Acesso em 17 de jul. de 2016.

SILVA, N. A.; PIOVESAN, Juliane. C. Música e Ludicidade: A importância da Música para o ambiente hospitalar. In: Novos Olhares: Narrativas e Mídias na Escola, 2014, Frederico Westphalen. Novos Olhares: Narrativas e Mídias na Escola. Frederico Westphalen: Frederico Westphalen: Uri, 2014. p. 71.

UNIFESP. Projeto Político Pedagógico Campus Baixada Santista, 2006. Disponível em: <http:// www2.unifesp.br/homebaixada/projetopedagogico_baixada.pdf>. Acesso em 18 de jul. de 2016.

Recebido para publicação em 23/9/2016 e aprovado em 20/11/2016. 